Review Article

\title{
Cutaneous Leishmaniasis: The Complexity of Host's Effective Immune Response against a Polymorphic Parasitic Disease
}

\author{
Áurea Gabriel ${ }^{\mathbb{D}}$, Ana Valério-Bolas, Joana Palma-Marques, Patrícia Mourata-Gonçalves, \\ Pedro Ruas $\mathbb{D}$, Tatiana Dias-Guerreiro $\mathbb{D}$, and Gabriela Santos-Gomes $\mathbb{D}$
}

Global Health and Tropical Medicine (GHTM), Instituto de Higiene e Medicina Tropical (IHMT), Universidade Nova de Lisboa (UNL), Rua da Junqueira 100, 1349-008 Lisboa, Portugal

Correspondence should be addressed to Gabriela Santos-Gomes; santosgomes@ihmt.unl.pt

Received 31 December 2018; Revised 5 October 2019; Accepted 22 October 2019; Published 1 December 2019

Academic Editor: Kurt Blaser

Copyright (C) 2019 Áurea Gabriel et al. This is an open access article distributed under the Creative Commons Attribution License, which permits unrestricted use, distribution, and reproduction in any medium, provided the original work is properly cited.

\begin{abstract}
This review is aimed at providing a comprehensive outline of the immune response displayed against cutaneous leishmaniasis (CL), the more common zoonotic infection caused by protozoan parasites of the genus Leishmania. Although of polymorphic clinical presentation, classically CL is characterized by leishmaniotic lesions on the face and extremities of the patients, which can be ulcerative, and even after healing can lead to permanent injuries and disfigurement, affecting significantly their psychological, social, and economic well-being. According a report released by the World Health Organization, the disability-adjusted life years (DALYs) lost due to leishmaniasis are close to 2.4 million, annually there are 1.0-1.5 million new cases of CL, and a numerous population is at risk in the endemic areas. Despite its increasing worldwide incidence, it is one of the so-called neglected tropical diseases. Furthermore, this review provides an overview of the existing knowledge of the host innate and acquired immune response to cutaneous species of Leishmania. The use of animal models and of in vitro studies has improved the understanding of parasite-host interplay and the complexity of immune mechanisms involved. The importance of diagnosis accuracy associated with effective patient management in CL reduction is highlighted. However, the multiple factors involved in CL epizoology associated with the unavailability of vaccines or drugs to prevent infection make difficult to formulate an effective strategy for CL control.
\end{abstract}

\section{Introduction}

Leishmaniases are anthroponotic and zoonotic diseases of global public health significance caused by obligatory intracellular digenetic parasites of the genus Leishmania [1-3]. These parasites are transmitted to human beings and mammalian hosts by the bite of infected sand flies of the Phlebotomus genus in the Old World and Lutzomyia in the New World, generating cutaneous or visceral leishmaniasis [4, 5]. More than 20 Leishmania species have been identified worldwide, according to the WHO $[1,5]$. Several species of Leishmania, belonging to both Leishmania and Viannia subgenus, cause CL in humans, including L. tropica, L. major, and $L$. aethiopica in the Old World and also L. mexicana, $L$. amazonensis, $L$. venezuelensis, $L$. braziliensis, $L$. shawi, $L$. guyanensis, L. panamensis, and L. peruviana that are only found in the New World $[2,5,6]$ (Table 1). Differences among Leishmania species can lead to diverse clinical manifestations and therapeutic responses [7-9]. The knowledge about the complex interactions between these species and the respective hosts, their geographical distribution, histopathological effects, clinical lesions, and immune evasion still need to be deepened $[2,4,5,7]$. In general, cutaneous species cause skin and mucous membrane lesions, which can persist for a long time in patients suffering from the disease and can also relapse during treatment [10-12]. Some CL patients can develop permanent injuries, which can leave them disfigured and stigmatized for life $[11,13,14]$. Thus, this review is aimed at providing a comprehensive outline of the immune response generated against the cutaneous species of Leishmania, evidencing the need for further studies able to deepen the understanding of protective immune mechanisms and pointing out opportunities that might be explored to further reduce CL threat. 


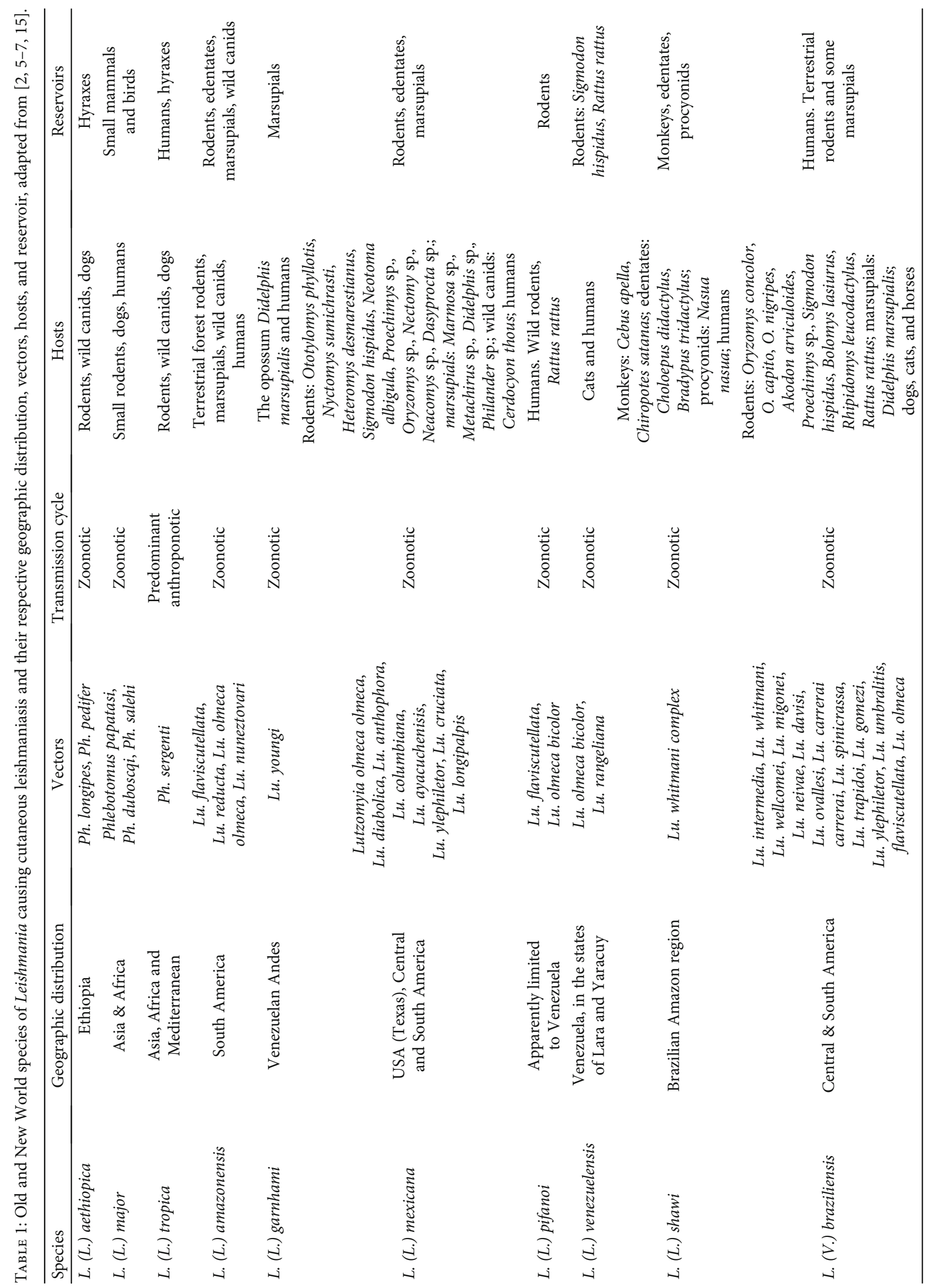




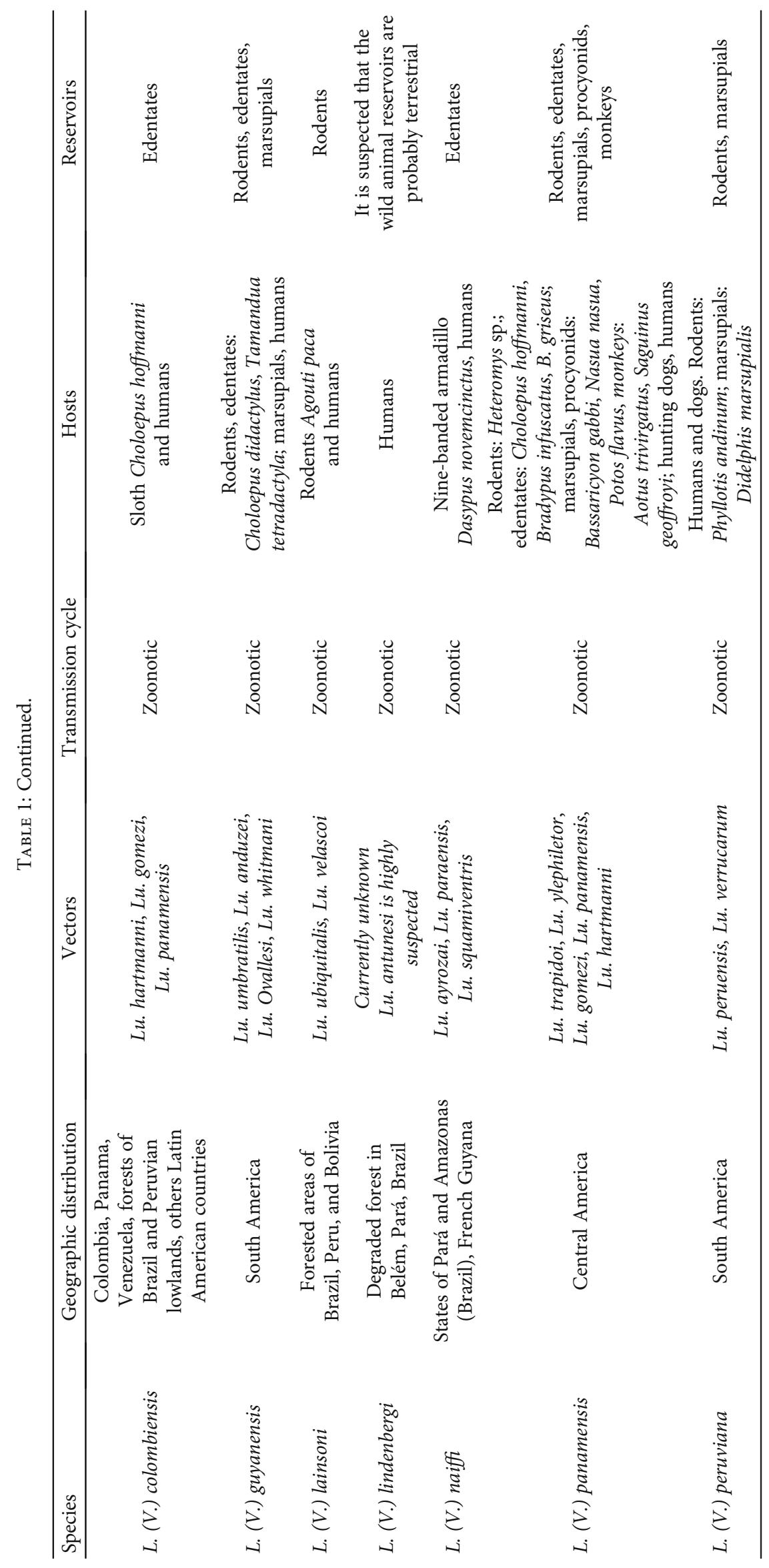




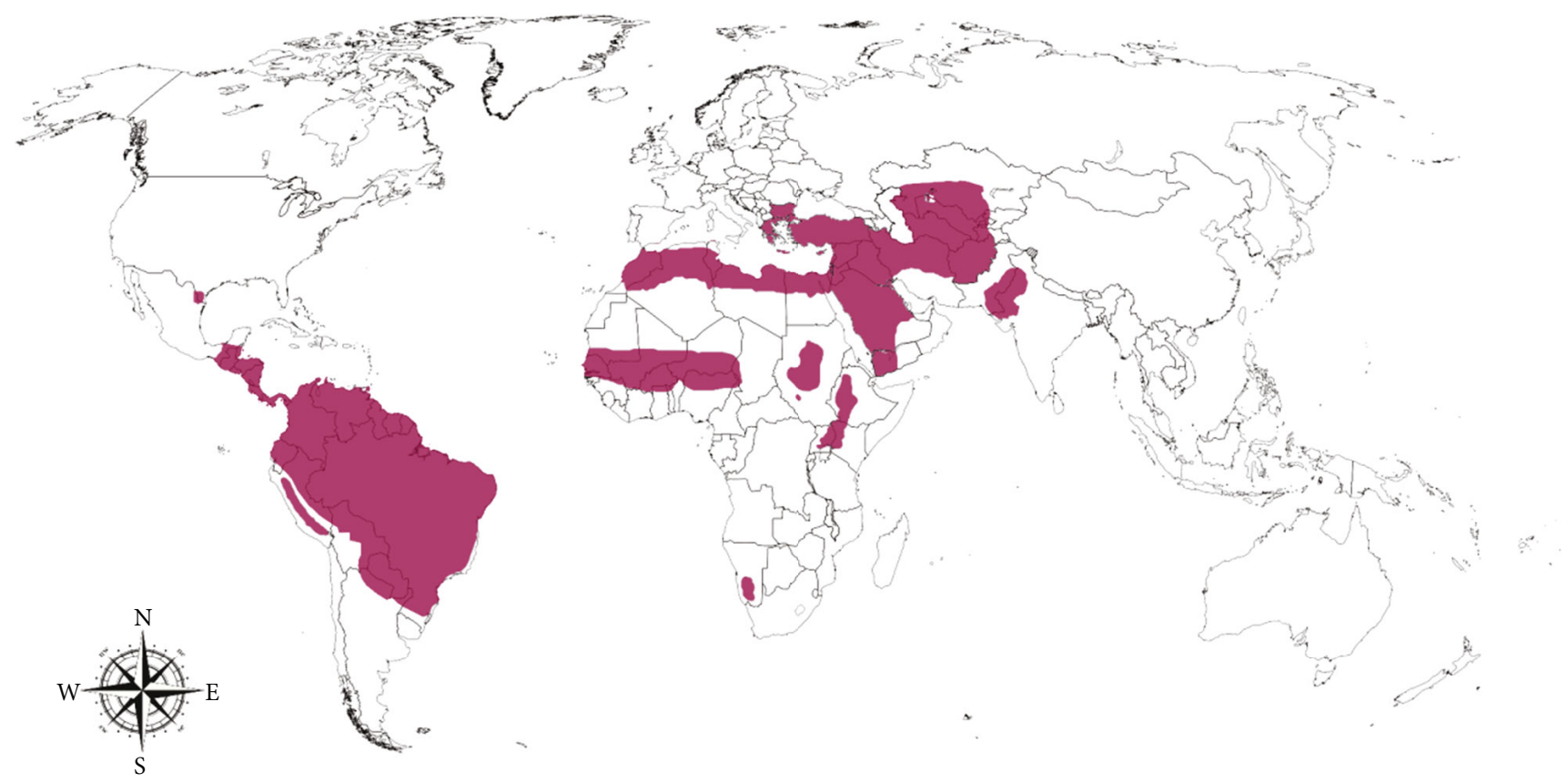

Figure 1: Worldwide distribution of cutaneous leishmaniasis, adapted from $[1,15,18]$.

\section{Cutaneous Leishmaniasis Has a Wide Geographic Distribution and Present Polymorphic Clinical Features}

Cutaneous leishmaniasis is considered the most common form of a Leishmania infection, affecting approximately 0.7 million to 1.2 million human beings $[1,14,15]$. This clinical form is prevalent in more than 90 countries with a proven endemic transmission in tropical and subtropical areas of the world, including rural, rainforests, arid areas, semiurban, and urban areas $[4,15,16]$. According to Maia-Elkhoury et al. [16], increased number of cases may be attributed to behavioral and environmental changes, determined mainly by climate, social, and economic conditions that influence Leishmania transmission.

CL is present in the southern USA, where occasional cases were reported in the States of Texas and Oklahoma, Central and South America, being the majority of CL cases reported in Brazil and Peru [16-18], and in the Old World, at North and East Africa, Middle East, and Western and South Asia [18-20] (Figure 1). In these areas, some cities show very high notification rates for new CL cases, like Aleppo (Syria, Western Asia) with around 12.000 new cases each year [19-21].

Leishmania lesions without pain or pruritus are common, but in some patients can be painful, especially if ulcerative lesions become secondarily infected with bacteria or if these lesions are near a joint [22]. CL may range between a limited form, presenting only one or few localized lesions, to a disseminated form with multiple lesions (Table 2), including hypodermal, verrucous, sporotrichoid, impetigoid, hemorrhagic, erysipeloid, chancriform, lupoid, papular, psoriasiform, and ulcer-crusted lesions [11, 23, 24].
The lesions may start out as nodules in approximately $20 \%$ of cases during acute infections and persist in chronic infection [1]. Depending on the clinical type and stage, the epidermis may be overlying a dense dermal infiltrate, containing predominantly histiocytes, lymphocytes, and plasma cells [25]. Several patients with American CL may develop regional lymphadenopathy, occasionally bubonic, nodular lymphangitis (sporotrichoid-like subcutaneous nodules), and satellite lesions [1].

In epidemic regions of Western Asia, where cases of $L$. tropica advanced to aggressive and prolonged disease courses, the lesions impinged and possibly hindered the function of vital sensory organs, including olfactory perception and vision [19].

\section{Competence of Innate and Acquired Immune Response Determines Infection Outcome and Cutaneous Leishmaniasis Severity}

The dissemination and persistence of Leishmania parasites in the immunocompetent host depends on continuous parasite strategies able to modulate and subvert innate and adaptive immune response [25-27]. According to in vitro studies, the host genetic background, Leishmania species, and different parasite isolates can influence immune response [28]. Increasing interest in studying the immune response against cutaneous species of Leishmania in different animal models (such as susceptible BALB/c mice, resistant C57BL/6 mice, and nonhuman primates) has contributed to an improved understanding of specific parasite-host interactions and highly complex pathways of immune mechanisms underlying CL immunopathology $[25,29,30]$. However, a full understanding of the immune mechanisms that are activated 
TABLE 2: Clinical presentation and delayed-type hypersensibility (DTH) of cutaneous Leishmania species in the world, adapted from $[2,82,90]$.

\begin{tabular}{|c|c|c|c|}
\hline Subgenus & Species & Main clinical presentation & DTH (skin test) \\
\hline \multirow{5}{*}{ Leishmania } & L. major & Localized & - \\
\hline & L. tropica & Localized & $\mathrm{DTH}+$ \\
\hline & L. aethiopica & Localized & - \\
\hline & L. mexicana & $\begin{array}{l}\text { Localized } \\
\text { Borderline disseminated } \\
\text { Anergic diffuse }\end{array}$ & $\begin{array}{l}\mathrm{DTH}+ \\
\mathrm{DTH}- \\
\mathrm{DTH}-\end{array}$ \\
\hline & L. amazonensis & $\begin{array}{c}\text { Localized } \\
\text { Borderline disseminated } \\
\text { Anergic diffuse } \\
\end{array}$ & $\begin{array}{l}\text { DTH - } \\
\text { DTH - } \\
\text { DTH - }\end{array}$ \\
\hline \multirow{12}{*}{ Viannia } & L. panamensis & $\begin{array}{l}\text { Localized LC } \\
\text { Borderline disseminated } \\
\text { Mucocutaneous }\end{array}$ & $\begin{array}{c}\text { DTH + } \\
\text { DTH - } \\
\text { DTH }++++\end{array}$ \\
\hline & L. braziliensis & $\begin{array}{l}\text { Localized } \\
\text { Borderline disseminated } \\
\text { Mucocutaneous }\end{array}$ & $\begin{array}{c}\text { DTH + } \\
\text { DTH - } \\
\text { DTH }++++\end{array}$ \\
\hline & L. peruviana & One or few lesions & - \\
\hline & L. venezuelensis & $\begin{array}{l}\text { Single and multiple skin lesions } \\
\text { Disseminated nodules } \\
\text { (confused with diffuse) }\end{array}$ & - \\
\hline & L. pifanoi & Diffuse & - \\
\hline & L. guyanensis & $\begin{array}{l}\text { Single and multiple skin lesions } \\
\text { Rare cases of mucocutaneous }\end{array}$ & - \\
\hline & L. shawi & $\begin{array}{l}\text { Single and multiple skin lesions } \\
\text { Cases of multiple lesions, clearly due } \\
\text { to metastases, are occasionally seen }\end{array}$ & - \\
\hline & L. colombiensis & Single and multiple skin lesions & - \\
\hline & L. naiffi & Localized & - \\
\hline & L. lainsoni & Localized & - \\
\hline & L. lindenbergi & Localized & - \\
\hline & L. garnhami & Localized & - \\
\hline
\end{tabular}

or inactivated in CL patients is crucial for the reduction of disease incidence to a level that would have a minimal impact on public health.

Immune defense is characterized by two principal mechanisms, the innate immune response that is activated early during the primary stage of the infection and the adaptive immune response, which is the second line response. The bridge between these two responses is accomplished by antigen-presenting cells (APCs) and by cytokines released into the microenvironment by effector immune cells.

\subsection{Inactivation of a Complement System Seems to Favor the} Establishment of Parasite Infection. The complement system plays a critical role in the innate immune defense. Plasma proteins that constitute the complement system are implicated in the activation of classical (CP), alternative (AP), and lectin pathways (LP). Complement activation triggers the stimulation of proteolytic cascades, generating different molecules, such as anaphylatoxins, opsonins, and the membrane attack complex. At the end of the complement cascade, pathogens undergo lysis and opsonization and also an inflammatory response occurs.

In vitro studies have shown that noninfective Leishmania promastigotes are susceptible to complementmediated lysis and that infective metacyclic promastigotes can actively resist [31].

Once in the dermis of mammals, infective promastigotes activate the complement system, and then, the parasite first survival mechanism comes into action, inhibiting complement cascade $[32,33]$.

Manipulation of the complement cascade is achieved through the inactivation of opsonins to promote macrophage $(M \Phi)$ attraction $[26,30]$. Previous studies have shown that LP is efficiently activated, since mannose-binding lectin, a protein that binds to the lipophosphoglycan of several microorganisms, including Leishmania, initiates the proteolytic cascade causing pathogen lysis [33-35]. Moreover, LP activation triggers $\mathrm{C} 3$-convertase that converts $\mathrm{C} 3$ in $\mathrm{C} 3 \mathrm{~b}$ directing AP activation $[34,36]$.

Infective Leishmania promastigotes have developed mechanisms to subvert AP activation [37]. 


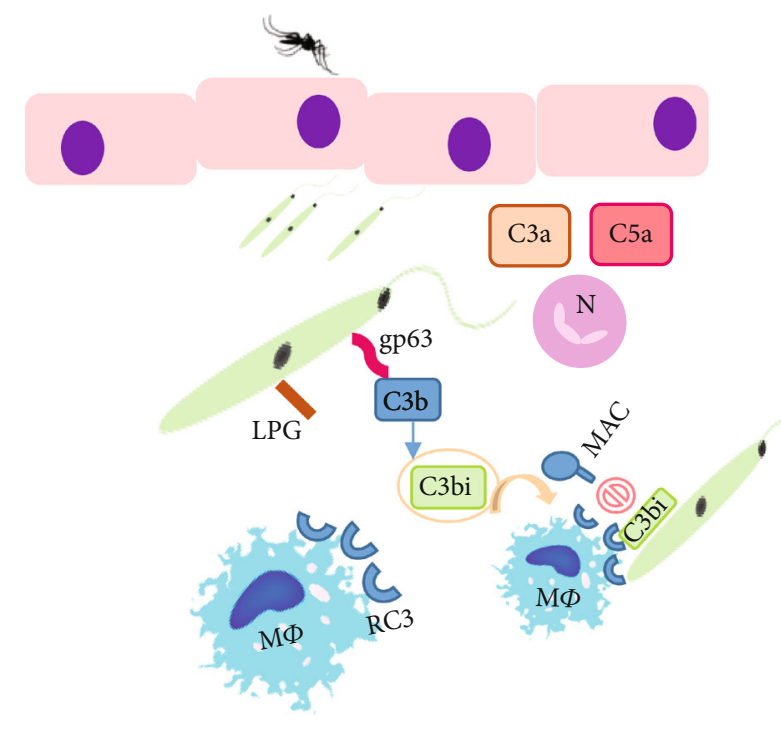

FIGURE 2: Inoculation of Leishmania promastigotes in the host dermis by the sand fly triggers the activation of the complement cascade. C3 convertase undergoes proteolytic cleavage, giving origin to the complement factors C3a and C5a. These chemotactic factors attract neutrophils $(\mathrm{N})$ and macrophages $(\mathrm{M} \Phi)$ to the infection site and induce the expression of the respective receptors. On the parasite membrane, the surface glycoprotein of $63 \mathrm{kDa}$ (gp63) can convert C3b to the inactive form (C3bi), which avoids the assembly of the lytic complex (MAC) on the parasite surface. In turn, C3bi binds to the MФ receptor (RC3), promoting fast parasite phagocytosis.

It was early found that the Leishmania surface glycoprotein captures C3b molecules [26, 30]. Upon the binding of C3 molecules to the glycoprotein of $63 \mathrm{kDa}$ (gp63), C3b becomes inactivated (iC3b), which prevent the generation of $\mathrm{C} 3$-convertase [37]. iC3b that remains attached to the parasite surface is recognized by the complement receptor-3 that triggers promastigote phagocytosis by $\mathrm{M} \Phi$ (Figure 2). Once uptake by $\mathrm{M} \Phi$, parasite differentiates into the amastigote form, which have the right conditions to initiate replication $[26,30]$.

Complement activation by $L$. mexicana membrane components was reported to cause the depletion of complement factors [37]. Complement exhaustion can drive the complement-independent parasite uptake by polymorphonuclear neutrophil granulocytes (PMNs), which can prolong parasite survival $[30,32]$. Thus, the innate immune response drove by the complement system of the host seems to negatively impact on CL caused by L. mexicana.

Even so, previous studies in BALB/c mice showed that complement can diminish the spreading of L. amazonensis parasites in cutaneous lesions [38] and in vitro studies revealed that $L$. tropica amastigotes were susceptible to complement lysis [39], suggesting that during infection amastigotes can be susceptible to the complement system.

3.2. Neutrophils Seem to Have a Dual Effect Delaying the Early Establishment of Infection and Later One Favoring Lesion Pathology. Shortly after mammal infection by sand fly inoculation, infective metacyclic promastigotes have to evade host innate immunity to survive $[25,30]$.

Polymorphonuclear neutrophils (PMNs) are the first host cells that migrate to the site of Leishmania infection (as well as tissue $\mathrm{M} \Phi$ ), probably in response to sand fly saliva [40-42] that is inoculated together with parasites. These short-lived cells armed with a set of intracellular and extracellular mechanisms can arrest and kill pathogens [30, 32].

When encountering Leishmania, PMNs can internalize the parasite, generate an array of intracellular and extracellular microbicidal factors, such as reactive oxygen species, exocytosis of granule content rich in serine proteases that can damage the parasite membrane, and also emit weblike sticky structures (neutrophil extracellular traps (NETs)) to the extracellular space which can entrap and inactivate parasites, producing a proinflammatory environment [3032]. However, despite the diverse mechanisms that PMNs have to contain pathogens, Leishmania parasites can survive, establishing infection and causing disease [30, 32, 33].

In the model of PMN intracellular infection, neutrophils can be used as "Trojan horses" assuring parasite survival and internalization by macrophages $(M \Phi)$, the definitive host cells, which also avoid the activation of $M \Phi$ killing mechanisms. Other studies performed with $L$. major revealed that mouse apoptotic PMNs can release viable parasites in the vicinity of surrounding $M \Phi$, favoring parasite uptake by $\mathrm{M} \Phi$ (Trojan rabbit mechanism) [28, 43].

The role of PMNs in controlling the dissemination of parasites at the early phase of cutaneous Leishmania infections has been studied in vitro and in experimental animal models [32]. An in vitro study showed that mouse neutrophils exposed to L. guyanensis, L. shawi, and L. amazonensis produced superoxide, released enzymes in the extracellular space, and generated NETs. However, L. guyanensis and $L$. shawi inhibited enzymatic activity and L. amazonensis reduced the NET emission, pointing towards the modulation of PMN extracellular effector mechanisms by cutaneous species of Leishmania [32]. Recent studies performed in the mouse model showed that PMN depletion accelerated the spreading of $L$. major and L. amazonensis parasites, leading to a more severe foot-pad swelling, which indicates that PMNs have a role in restraining parasite infection and in controlling the development of cutaneous lesions [44, 45]. Neutrophils seem to recognize these parasites through pattern recognition receptor- (PRR-) dependent mechanisms, such as toll-like receptor (TLR) 2, thereby activating downstream pathways that could compromise parasite survival $[32,46,47]$.

After in vitro parasite stimulation, bloodstream PMNs from $L$. braziliensis-symptomatic patients were not more microbicidal than PMNs obtained from healthy subjects but presented a predominately proinflammatory profile, possibly influencing microenvironment and leukocyte recruitment $[27,47]$. When in contact with parasites, PMNs isolated from healthy blood donors and from patients with American CL released NETs that contained and retained parasites, promoting its destruction as well as stimulated $\mathrm{M} \Phi$ activity in order to control parasite infection $[48,49]$. It was also verified in vitro that the interaction of $L$. amazonensis- 
exposed apoptotic or necrotic neutrophils with $M \Phi$ drove the initial $M \Phi$-parasite infection, determining the infection outcome [50]. Taken together, these findings highlight the crucial role of PMNs in early infection, controlling cutaneous Leishmania parasites and delaying infection establishment and the progress of lesions [32, 50].

Neutrophils are present in unhealing cutaneous lesions, and recent studies performed in both humans and mice have shown that PMN infiltrates in cutaneous lesions induce immune-mediated tissue pathology [28, 40,51].

Furthermore, PMN can present heterogeneous functional activity against different cutaneous Leishmania species and within the same species, indicating specific parasite immune recognition [9]. Different L. braziliensis isolates can promote specific activation of human PMNs. PMNs can inactivate Leishmania parasites or can favor infection, hosting viable infective parasites that can be delivered to the host cell. These findings support the hypothesis that PMNs can select the most infective parasites and inactivating the less virulent ones, which can generate novel avenues to explore the development of strategies underlying the modulation of PMN recruitment and activity that can direct lesion healing [52].

Although widely recognized as not having a key role in parasitic diseases caused by protozoa, in vivo studies highlighted eosinophil recruitment to L. amazonensis and L. major lesions [53-55]. It was also described that L. braziliensis patients that were in the early phase of lymphadenopathy exhibited cellular infiltrates enriched in eosinophils. [53]. Moreover, in L. mexicana early infection, eosinophils have been observed within the proximity of degranulating mast cells at the parasite inoculation site [56], pointing towards the occurrence of crosstalk between these two cells that could favor parasite clearance.

3.3. Cytotoxic Innate Cells Can Aid in the Control of Dermal Infection. After PMN recruitment, natural killer (NK) cells are also recruited in the early stage of Leishmania infection $[25,31]$. NK cells are large granular leukocytes that play a key role in the innate immune response [57]. These cells are crucial in defining disease severity, restricting early parasite dissemination, and mediating direct lysis of parasitized cells, conferring protective immune response against Leishmania infection. Studies performed in the mouse model with $L$. amazonensis and $L$. major show the increase of parasite burden as a direct consequence of NK cell depletion [5860]. These cells early release proinflammatory cytokines, such as interferon- (IFN-) $\gamma$ that favors the differentiation of $\mathrm{CD}_{4}^{+}$Th1 cells and together with tumor necrosis factor(TNF-) $\alpha$ activates the $M \Phi$ killing machinery $[33,59,60]$. However, it seems that Leishmania parasites have some mechanisms directed to suppress NK activity [58-60].

Studies performed in L. major-infected mice have demonstrated that NK cells exhibit a strong activation that peaks at $12 \mathrm{~h}$ to $48 \mathrm{~h}$ after infection, after which a steady decline tends to occur [61]. Some authors associate this suppression with the ability of this parasite to inhibit the production by neutrophils of NK cell-attracting chemokine IP-10 (CXCL9), which can prevent the activation of NK cells, therefore avoid- ing a continuous onset of NK cells from the bloodstream [62]. Furthermore, it was demonstrated that L. major promastigotes, the respective crude antigen, and gp63 can inhibit IFN- $\gamma$ production by NK cells. gp63 seems to be able to bind to human NK cells, inhibiting cell's ability to produce IL-2 and downregulate some of the NK cell receptors, such as CD16 and CD56 [63]. In the case of L. tropica and L. amazonensis amastigotes, suppression of NK cell activity seems to be associated with low levels of IL-12. This interleukin released by DC determines NK cell activation. In human beings, it has been demonstrated an increase of $\mathrm{CD} 56^{+} \mathrm{NK}$ cells in sites of healing lesions [64], thus suggesting a protective role of these cells in human leishmaniasis.

Although it was demonstrated that NK cells protect against CL, some studies indicate that these cells play a minor role $[31,53]$. Thus, it is possible that NK cells can aid the immune system fighting against infection, but the involvement of these cells is still poorly studied in human CL and remains controversial in experimental murine leishmaniasis [53, 54, 65]. However, NK cell activity differs between patients with $L$. mexicana localized (LCL) and diffuse (DCL) CL. Reduced NK cell numbers in DCL patients associated with TLR downexpression and low cytokine production can be related to disease severity [65].

Therefore, it is possible that the regulation of NK cells can lead to a new opportunity for targeting CL control.

\subsection{Antigen-Presenting Cells Have a Key Role in Directing T} Cell Effector Activity. Promastigotes are also taken up by $\mathrm{M} \Phi$ that are the final host cells for Leishmania parasites [56]. In spite of being the parasite preferential host cells, since it is inside $M \Phi$ that replicates, these cells still are an immune barrier that parasites must overcome to persist in the host $[26,30]$. Within $M \Phi$ phagolysosome, promastigote forms undergo morphological differentiation into small and nonmotile amastigotes able to resist to host cell killing mechanisms and survive under mammal high temperature (when compared to the sand fly) $[30,56]$. Amastigotes replicate and promote the chronicity of cutaneous infection within dermal $M \Phi[30,56]$. Leishmania parasites can induce $M \Phi$ differentiation into two distinct phenotypes: M1 and M2 [30] (Figure 3). M1-M $\Phi$, also called classically activated $\mathrm{M} \Phi$, are stimulated by the proinflammatory cytokines IFN$\gamma$ and TNF- $\alpha$. These cytokines induce the expression of nitric oxide (NO) synthase 2 (NOS2), which degrades arginine into $\mathrm{OH}$-arginine and subsequently into $\mathrm{NO}$ and citrulline [31, $66,67]$. NO can be further metabolized to other reactive nitrogen species, while citrulline can enter in the citrullineNO cycle and synthesize NO [66-68]. This mechanism is responsible for NO-dependent leishmanicidal activity, which plays a key role against Leishmania infection [67, 68]. Although M1-MФ response usually leads to parasite control, it also promotes necrosis of cutaneous lesions in consequence of an intense immune response that favors the development of severe wounds [69].

$\mathrm{M} 2-\mathrm{M} \Phi$, also known as alternatively activated $\mathrm{M} \Phi$, can be induced by different immunomodulators, including $\mathrm{M} \Phi$ colony-stimulating factor (M-CSF), interleukin- (IL-) 4, and IL-1. According to stimulation, M2-M $\Phi$ can be 


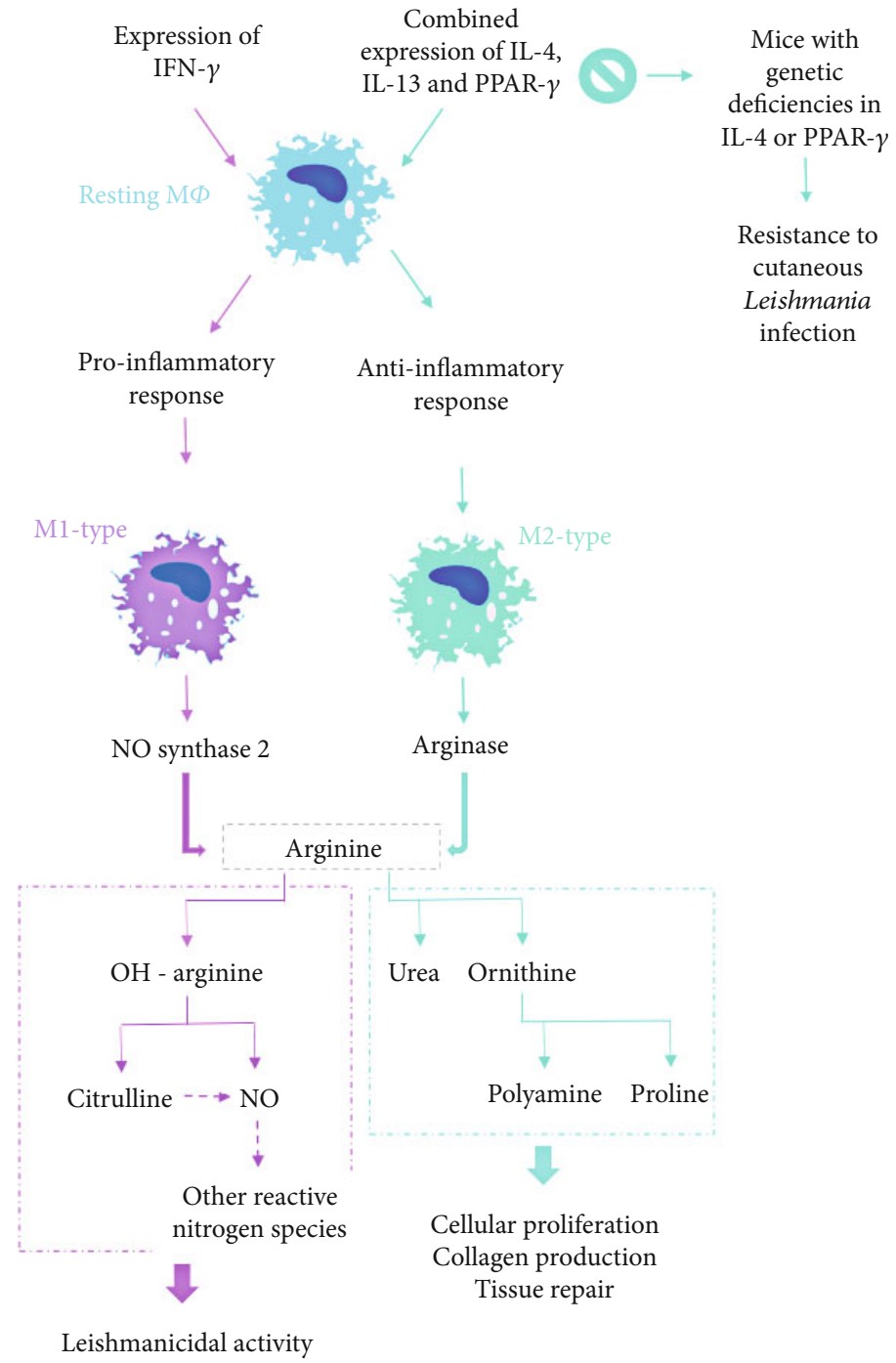

FIGURE 3: Differentiation of macrophage effector mechanisms against cutaneous species of Leishmania influences parasite fate and disease severity. IL: interleukin, IFN: interferon, $M \Phi$ : macrophages, NO: nitric oxide, PPAR: peroxisome proliferator-activated receptor.

phenotypically identified as M2a, M2b, M2c, or M2d, which seems to be involved in different immune activities.

$\mathrm{M} 2-\mathrm{M} \Phi$ activate the arginine pathway by expressing arginase, an enzyme that hydrolyzes arginine into urea and ornithine. Ornithine is further metabolized into polyamine and proline, which induce cellular proliferation, collagen production, and tissue repair [68-70].

Moreover, in 2007, Odegaard et al. [71] reported that peroxisome proliferator-activated receptor- (PPAR-) $\gamma$ has a role in the maturation of alternatively activated $M \Phi$ and showed that disruption of PPAR- $\gamma$ in myeloid cells prejudices M2$M \Phi$ activation [71, 72]. In fact, several studies obtained evidence that $\mathrm{M} 2-\mathrm{M} \Phi$ are associated with Leishmania infection. In the case of $\mathrm{CL}$, the involvement of PPAR- $\gamma$ in $\mathrm{M} 2-\mathrm{M} \Phi$ activation was only reported to $L$. major, L. amazonensis, and L. mexicana infection $[30,37,69]$.

Although activation of M1-M $\Phi$ by both IFN- $\gamma$ and TNF- $\alpha$ results in control of infection, this observation might not be a true predictor of disease progression to all cutaneous species of Leishmania, since it is also reported that IFN- $\gamma$-activated $\mathrm{M} \Phi(\mathrm{M} 1-\mathrm{M} \Phi)$ are not able to incapacitate $L$. amazonensis amastigotes, favoring parasite survival $[30,50]$. In resistant mice, L. major infected MФs will trigger $\mathrm{T}$ helper 1 (Th1) cells, directing the production of IFN- $\gamma$ and, consequently, activating the inducible nitric oxide synthase (iNOS) and leading to differentiation of M1-MФ [66, 73]. This will lead to parasite inactivation and slow down parasite dispersion [74].

Furthermore, in patients with diffuse CL due to L. amazonensis, arginase, polyamines, and prostaglandin E2, a lipid compound derived from fatty acids commonly associated with inflamed tissues seems to lessen local inflammatory immune response when compared with patients with local CL [75]. Thus, it is possible that together, these mediators favor the development of diffuse CL.

More recent studies have demonstrated that the arginase of $L$. amazonensis can mediate the posttranscriptional regulation of $M \Phi$ microRNAs [75]. The absence of parasitic arginase seems to favor NOS2 upregulation and the consequent increase of NO production, which can lead to parasite 
inactivation. Besides, a further study by Badirzadeh et al. did not found significant correlations between the activity of $L$. major arginase and the number, size, and duration of patient lesions $[76,77]$. On the other hand, in the susceptible mice, IL-4, IL-6, and IL-10 were responsible for the suppression of iNOS-associated mechanisms and differentiation of M2-M $\Phi[30,78]$.

Dendritic cells (DCs) and M $\Phi$ are important APCs that establish a bridge between innate and adaptive immunity. These cells present foreign antigens to helper $\mathrm{T}$ cells through class II molecules of major histocompatibility complex (MHCII) while these and other cell types can present antigens to cytotoxic $\mathrm{T}$ cells through class I molecules of major histocompatibility complex (MHCI). In addition to MHC molecules, costimulatory molecules are essential for $\mathrm{T}$ cell suitable activation. Downregulation of costimulatory molecules leads to impairment of signaling pathways and defective immune responses [79].

Several studies have shown that DCs can play a dichotomic functional role in the modulation of the host immune response, affecting the adaptive immune response and the disease outcome [78]. In L. amazonensis and L. braziliensis cutaneous lesions, dermal DCs (also called Langerhans cells) play distinct roles. In $L$. amazonensis patients, DCs are related to a Th2-type immune response, while in L. braziliensis patients, DCs are associated with a protective Th1 immune response [79].

On the other way, after in vitro restimulation, monocytes isolated from patients with CL caused by L. braziliensis showed a low expression of costimulatory molecules B7-1 (CD80) and B7-2 (CD86). Since costimulatory molecules are crucial for a proper $\mathrm{T}$ cell activation, $L$. braziliensis parasites appear to be able to regulate the patient immune response [80].

Like $M \Phi$, Leishmania also interferes with intracellular signaling in DCs [73, 78]. Modulation of DC activation by Leishmania parasites appears to be species-specific [30, 78]. Experimental studies with L. major, L. mexicana, L. amazonensis, and $L$. braziliensis suggested that migratory DCs increase the expression of MHC and costimulatory molecules $[30,73,78]$. Histopathological observations of human skin biopsies reveal variation in severity of the skin lesions, which may be related to the density levels of DC subsets exhibiting diverse phenotype that by directing the $\mathrm{T}$ cell immune response may affect disease severity $[3,81,82]$ (Table 2).

In experimental models, DCs process and provide the first contact of Leishmania antigens to $\mathrm{T}$ cells, leading to a preferential stimulation of IFN- $\gamma$ produced by $\mathrm{CD} 4^{+} \mathrm{T}$ cells $[30,82,83]$. On the other hand, other studies performed in L. major-infected mice place in evidence that dermal DC may induce the expansion of the Treg cell subset [84].

Although the role of DCs in CL is very complex, these cells can be used to develop novel avenues that can lead to the generation of alternative therapies and therapeutic vaccines to improve the treatment of infected patients [85].

DCs and MФs express PRRs that allow parasite detection on host skin. TLRs are the most studied, and some of them, such as TLR3, TLR4, TLR7, and TRL9 have shown to play a key role in innate sensing and recognition of
Leishmania by those cells [81]. This recognition is crucial to initiate the inflammatory response and control of parasite replication $[30,80]$.

After in vitro restimulation with parasite antigens, monocytes isolated from patients with LC caused by L. braziliensis showed upregulation of TLR9. Furthermore, it was found an association between the higher frequency of TLR9 ${ }^{+}$monocytes and lesion severity. The intracellular sensor TLR9, a transmembrane protein of endosomal compartments, binds to pathogen DNA triggering signal pathways that lead to a proinflammatory response. Thus, the upregulation of this sensor in CL patients points towards a release of proinflammatory cytokines, which do not seem to have a beneficial effect in reducing disease severity [80].

3.5. Interaction of Proinflammatory and Regulatory Lymphocyte Subsets Seems to Be the Hallmark of Cutaneous Leishmaniasis. B and T cells are key components of acquired immunity. B cells are responsible for generating antigenspecific antibodies (humoral response), and since they are APCs, they can also play a role in the activation of $\mathrm{T}$ cells [86-88]. These cells become activated after exposure to foreign antigens, which are internalized leading to the replication and differentiation of effector B cells and antibody released $[30,86]$. Several studies suggest that $B$ cells might be involved in the exacerbation of Leishmania infections, including cutaneous disease caused by $L$. tropica, $L$. mexicana, L. major, L. braziliensis, and L. amazonensis, though the mechanism behind it is still unknown $[87,89,90]$.

However, studies performed with $L$. major in resistant rodent models $(\mathrm{C} 3 \mathrm{H} / \mathrm{HeN}$ and $\mathrm{C} 57 \mathrm{BL} / 6)$ suggest that $\mathrm{B}$ cells might have a role in the development of immunity against Leishmania infection [91, 92]. Furthermore, Mukbel et al. [93] showed that soluble factors, like species-specific immunoglobulins, and both $\mathrm{CD} 4^{+} \mathrm{T}$ and $\mathrm{B}$ cells derived from $L$. major-infected mice that healed the infection played a key role in killing L. amazonensis intracellular parasites. Also, a more recent study reported by Gibson-Corley [94] showed that $\mathrm{B}$ cells from $\mathrm{C} 3 \mathrm{HeB} / \mathrm{FeJ}$ mice coinfected with $L$. major and $L$. amazonensis promote parasite killing while $\mathrm{B}$ cells from coinfected C57BL/6 mice were ineffective in controlling infection. Although, action mechanism of B cells is not well elucidated, these findings may indicate that $\mathrm{B}$ cells can be a good target for development of a therapeutic for dermal leishmaniasis, since these cells seem to have a role in CL control in resistant mouse models [95].

The control of Leishmania infection and disease progression has long been associated with the generation of proinflammatory and anti-inflammatory immune response [30]. A sustained Th1 response characterized by elevated IL-12, IL-2, IFN- $\gamma$, and TNF- $\alpha$ and downmodulation of IL- 4 and IL-10 production promotes $M \Phi$ activation (Figure 4) and seems to be crucial for host control of Leishmania parasite burden and clinical cure $[30,82,83]$.

On the other hand, Th2-related cytokines (IL-4, IL-5, IL10 , and IL-13) inhibit $M \Phi$ activation, contributing to parasite survival $[30,83,85]$.

In some CL clinical forms, a mixed Th1/Th2 immune response occurs during active infection, tending Th2 


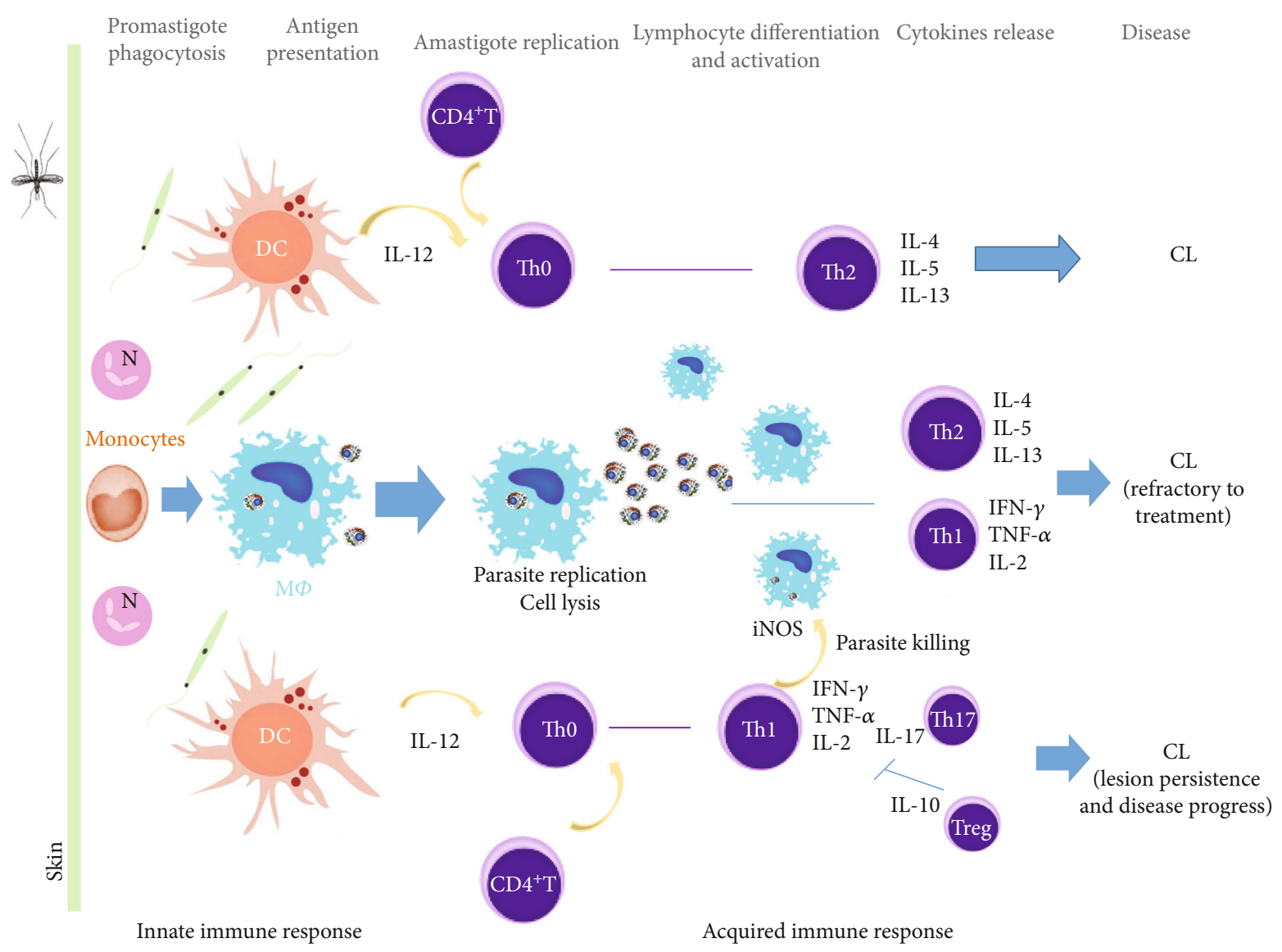

Figure 4: Activation of host immunity by cutaneous species of Leishmania. After skin infection, Leishmania promastigotes are uptake by phagocytes. IL-12 is secreted by activated DCs, and parasite antigens are presented by APCs, resulting in lymphocyte activation and secretion of proinflammatory (IL-2, IFN- $\gamma$, and TNF- $\alpha$ ) cytokines that can activate M $\Phi$ microbicide mechanisms, leading to parasite inactivation. When IL-4, IL-5, and IL-13 predominate parasite replicates, allowing disease establishment. Differentiation of Th17 lymphocytes lead to a strong inflammatory environment that could cause tissue damage. Regulatory $\mathrm{T}$ cells inhibit lymphocyte activity promoting immune homeostasis and favoring disease progress. CL: cutaneous leishmaniasis; DC: dendritic cells, IFN: interferon; IL: interleukin; MФ: macrophages; N: neutrophils; NO: nitric oxide; Th: T helper cell; Th0: naïve T cells; TNF: tumor necrosis factor; Treg: regulatory $\mathrm{T}$ cells.

response to be dominant when both types of responses are activated [10]. The expansion of Th2 response is associated with the progression and chronicity of cutaneous lesion that is frequently refractory to classical leishmanial treatment, leading to severe mutilations $[10,83,85]$.

Studies evaluating the production of cytokines in CL patients caused by L. guyanensis have shown high levels of IL-2 and IFN- $\gamma$ [7]. In lesions, it has been detected a high density of Th2-related cytokines, particularly of IL13. Moreover, these patients also can exhibit reduced or nondetectable antigen recognition associated with high levels of IL-10 and IL-5 and also lower specific antibody titers. In conclusion, enhanced Th2-type cytokines, which restrain Th1-type response, lead to an immune environment permissive to parasite replication [7, 96, 97]. Thus, L. guyanensis infection affects the expansion of antigenspecific $\mathrm{T}$ lymphocyte clones, causing low lymphocyte proliferation and decreasing IFN- $\gamma$ production. Limited cellular and humoral responses during L. guyanensis infection may explain a high parasitic load and the recurrence of the disease [7].
Advances in the understanding of CL progression indicate that cellular interactions are more complex than the Th1/Th2 paradigm. Cutaneous Leishmania infection follows a complex set of interactions that can lead to the differentiation of the Th17 cell subset, which is characterized by releasing IL-17 [40, 98]. This cytokine, recognized as a proinflammatory modulator, induces other cells to release inflammatory mediators that ultimately promote PMN recruitment to the infection site, sustaining an inflammatory environment that can be associated with lesion persistence.

LC patients infected with L. amazonensis or L. guyanensis exhibited higher levels of Th17 lymphocytes [40]. In human infections caused by L. major, L. tropica, L. amazonensis, L. braziliensis, L. guyanensis, or L. panamensis was observed a high IL-17 production, pointing towards PMN recruitment and $M \Phi$ activation, which can be related to disease development and lesion severity [40,99]. In murine studies, Th17 cells were associated with tissue destruction $[40,51,88,100]$.

Regulatory T (Treg) lymphocytes are considered a crucial cell subset to control the exacerbated inflammatory response, 
regulating disease pathology. The role of Tregs in the spectrum of CL immune responses varies across Leishmania species $[40,88,100]$. In L. major-infected mice, Tregs play varying roles in the disease outcome depending upon the genetic background and susceptibility of the host [101]. However, in the case of $L$. panamensis infection, Treg cells play a role in downregulating inflammatory cytokines, which appear to limit host cell recruitment leading to reduction of lesion size [101]. Hence, the role of Tregs and also of Th17 in $\mathrm{CL}$ is unclear, warranting further investigations able to evaluate cell dynamic and better understand the potential of being used as biomarkers of disease severity and a target for drug treatment.

L. major and L. braziliensis in vivo studies bring evidences that IL-10 subfamily is essential for the wound healing process, maintaining skin repair properties and limiting pathology independent of parasite control [85]. Other regulatory mechanisms mediated by cytokines must be explored in future studies for the control of Leishmania-induced immunopathology [102, 103].

Furthermore, it was reported that CL patients infected by $L$. braziliensis can present $\mathrm{CD} 4^{-} \mathrm{CD} 8^{-}$(DN) T lymphocytes expressing $\alpha \beta$ T cell receptors (TCR) and DN T cells expressing $\gamma \delta$ TCR. While $\alpha \beta$ DN T cell subset was associated with a more inflammatory environment, leading to antiparasitic activation of $\mathrm{M} \Phi, \gamma \delta \mathrm{DN}$ T cells seem to play a regulatory role, favoring the reduction of inflammatory response [103].

In CL, a proper local inflammatory immune response is crucial to contain and reduce parasite expansion. However, an extensive or excessive inflammatory response can cause tissue damage. Thus, the simultaneous finding of proinflammatory and regulatory cell subpopulations in CL patients seems to contribute to the balance between a protective immune response against the parasite and the natural intrinsic response that ensure the immune homeostasis.

NK T (NKT) cells, a specialized subpopulation of T lymphocytes, also seem to play a role during the early stages of Leishmania infections [91, 104, 105] (Figure 4). However, in L. major-infected mice, it was demonstrated that NKT cells appear to control parasite burden in skin lesions and in the spleen, but not in the lymph nodes [54], pointing towards an organ-specific role for these cells. Moreover, in the dermal lesions of $L$. braziliensis-infected patients, NKT cells with cytotoxic activity were identified [104].

\section{Challenges of Prevention, Diagnosis, and Treatment of Cutaneous Leishmaniasis}

Minimizing CL impact relies on prevention, diagnosis, and treatment, the three primary steps that must integrate developing new strategies for effective leishmaniasis control.

Prevention is the first pillar that needs to be ensured to achieve control of the disease. It encompasses (i) the reduction of population exposition to parasite vector, (ii) measures to diminish the role of vector and reservoirs in parasite transmission, (iii) awareness and education of the population at risk for this parasitic disease, (iv) availability of basic health care, and (v) monitoring of disease spread and incidence.
Vector control relies mostly on the use of insecticides, besides being toxic and needing a regular reapplication, which is a hassle for populations with low income and also generate a significant increase of insecticide-resistant vectors. Furthermore, the main reservoirs of the parasite are silvatic animals that can interact with the populations, which also increase the difficulty in controlling these parasites.

Monitoring of CL still is not an easy task since social stigma, war, poverty, and scarcity of access to health care largely affects most of the endemic regions that are associated with lack of equipment and of trained staff further aggravate these difficulties.

The diagnosis and treatment are interconnected, since the stage of disease progression and diagnosis accuracy highly influence the treatment efficacy. An early and accurate diagnosis and effective patient management are essential to reduce parasite transmission and CL increase.

In CL endemic areas, the accuracy of diagnosis must be made in the earlier clinical presentation to avoid the complications of advanced disease [106]. Specific approaches to treat CL patients have to take in consideration the etiologic agent, patient immune competence, clinical features, and arising complications in the course of Leishmania infection $[11,19]$. Atypical infections may require an accurate differential diagnosis with other possible coexisting infections, such as leprosy, tuberculosis, fungal infections, ecthyma, furuncle, carbuncle, North American blastomycosis, paracocciomycosis, yaws, prototheca infection, condyloma acuminate, sporotrichosis, syphilis, lupus vulgaris, cutaneous furuncular myiasis, tungiasis, xanthoma tuberosum, sarcoidosis, pyoderma gangrenosum, and neoplasm [107]. Conventionally, the prompt CL diagnosis is obtained by the identification of amastigotes forms (round intracellular forms with $1.5 \mu \mathrm{m}$ to $3 \mu \mathrm{m}$ ) of Leishmania in biopsy samples of skin lesion (gold standard) by optical microscopic observation [1]. Other methodologies may be either applied to the diagnosis of leishmaniasis, like skin histological analyses, in vitro biopsy culture, and molecular diagnosis [25]. Occasionally, the leishmanin skin test (LST), also called the Montenegro skin test (MST) and delayed-type hypersensitivity (DTH), is used in CL as a marker of cellular immune response (Table 2). When CL diagnosis has been unequivocally established, it is necessary to apply specific targeted therapy and manage the patient to control the infection $[12,14]$. In some cases, it is necessary to monitor adverse effects including myalgia, gastrointestinal disturbances, headache, anorexia, asthenia, fever, neurological alterations, and arrhythmia and also to use the medical imaging techniques, like magnetic resonance imaging (MRI) to show no cartilaginous destruction or paranasal involvement in severe cases [12,108].

Antileishmanial drugs applicable to CL are limited and display severe side effects, elevated costs, and usually require prolonged treatments [109]. The species of Leishmania involved in the infection, parasite resistance, and concomitant infections are key factors that influence the efficacy of the treatment $[110,111]$. Other treatment possibility is the use of thermotherapy; nevertheless, this technique is not widely available due to the cost of the devices and procedures required and the need of skilled health professionals to 
perform the treatment [112]. Recent studies about the specific interventions to treat CL in children provide evidences of the scarcity of data available to support treatment recommendations for this age range and of the unmet need to develop and test better treatment options for this vulnerable group [113].

The availability of effective, low cost, and safe treatments like prophylactic vaccines, drugs and therapeutic vaccines for cutaneous infection is not yet available for human leishmaniasis. Furthermore, other insurgent issues such as climate changes, migration of populations, and permissiveness of vectors can make more complex CL control, promoting disease spreading [16]. Climate changes can lead to the spreading of the vectors to nonendemic regions $[1,114]$. The dispersion of the vector allied with high vectorial capacity and permissiveness can facilitate the adaptation of the parasite in nonendemic areas, leading to the generation of new foci and increasing the risk of parasite transmission [3, 115, 116]. Furthermore, economic problems, natural disasters, and wars associated with mass migration and tourist travellers can lead to an increased risk of infection exposure [4, 20, 117].

\section{Closing Remarks}

Cutaneous leishmaniasis is an important public health problem worldwide. The spectrum of Leishmania infection can be subclinical, localized and disseminated, and relies on the immune competence of the host and on the infectivity of parasite species.

The fact of CL present high incidence mainly in areas with lack of economic resources, insufficient trained health professionals, and low awareness for the health issue of leishmaniasis allied with the lack of highly effective vector and reservoir control, treatments and no availability of a vaccine, creates an environment that promotes the CL propagation, turning the disease in pressing concern global health.

Together with the human description of the specific immune response, animal models have been used to extensively characterize the immune response to parasite infections caused by cutaneous species of Leishmania. Therefore, the investment in CL additional studies is urgent and essential, underlying the factors regulating immune pathological responses, which are needed for the implementation of more efficient and integrated control strategies and therapeutics. These efforts are indispensable for the populations affected by the disease, which are in desperate need of affordable and effective alternatives to the available treatments that are associated with parasite resistance and severe toxic effects.

\section{Conflicts of Interest}

None of the authors have any conflict of interest to declare.

\section{Acknowledgments}

The funding of this work was provided by the Portuguese Foundation for Science and Technology (FCT) through projects PTDC/CVT-CVT/28908/2017 and GHTM-UID/
Multi/04413/2013. Ana Valério-Bolas was awarded by a PhD scholarship (SFRH/BD/118067/2016) by FCT. Áurea Gabriel is thankful to Coordenação de Aperfeiçoamento de Pessoal no Ensino Superior (CAPES), Brazil.

\section{References}

[1] World Health Organization, Regional Office for the Eastern Mediterranean, Manual for case management of cutaneous leishmaniasis in the WHO Eastern Mediterranean Region, vol. 35, WHO Regional Publications, Eastern Mediterranean Series, 2014.

[2] R. Lainson, "The neotropical Leishmania species: a brief historical review of their discovery, ecology and taxonomy," Revista Pan-Amazônica de Saúde, vol. 1, no. 2, pp. 13-32, 2010.

[3] U. Sharma and S. Singh, "Insect vectors of Leishmania: distribution, physiology and their control," Journal of Vector Borne Diseases, vol. 45, no. 4, pp. 255-272, 2008.

[4] C. González, E. A. Rebollar-Téllez, S. Ibáñez-Bernal et al., "Current knowledge of Leishmania vectors in Mexico: how geographic distributions of species relate to transmission areas," The American Journal of Tropical Medicine and Hygiene, vol. 85, no. 5, pp. 839-846, 2011.

[5] A. L. R. Roque and A. M. Jansen, "Wild and synanthropic reservoirs of Leishmania species in the Americas," International Journal for Parasitology: Parasites and Wildlife, vol. 3, no. 3, pp. 251-262, 2014.

[6] L. W. F. Souza, S. V. T. Souza, and A. C. C. Botelho, "Comparative analysis of the geographic distribution of the histopathological spectrum and Leishmania species of American cutaneous leishmaniasis in Brazil," Anais Brasileiros de Dermatologia, vol. 87, no. 3, pp. 369-374, 2012.

[7] A. F. Borges, R. S. Gomes, and F. Ribeiro-Dias, "Leishmania (Viannia) guyanensis in tegumentary leishmaniasis," Pathogens and Disease, vol. 76, no. 4, pp. 1-10, 2018.

[8] S. M. Christensen, A. T. Belew, N. M. el-Sayed, W. L. Tafuri, F. T. Silveira, and D. M. Mosser, "Host and parasite responses in human diffuse cutaneous leishmaniasis caused by L. amazonensis," PLoS Neglected Tropical Diseases, vol. 13, no. 3, p. e0007152, 2019.

[9] B. S. McGwire and A. R. Satoskar, "Leishmaniasis: clinical syndromes and treatment," QJM: An International Journal of Medicine, vol. 107, no. 1, pp. 7-14, 2014.

[10] R. Reithinger, J. C. Dujardin, H. Louzir, C. Pirmez, B. Alexander, and S. Brooker, "Cutaneous leishmaniasis," The Lancet Infectious Diseases, vol. 7, no. 9, pp. 581-596, 2007.

[11] M. Z. Handler, P. A. Patel, R. Kapila, Y. al-Qubati, and R. A. Schwartz, "Cutaneous and mucocutaneous leishmaniasis: clinical perspectives," Journal of the American Academy of Dermatology, vol. 73, no. 6, pp. 897-908, 2015.

[12] H. J. C. De Vries, S. H. Reedijk, and H. D. F. H. Schallig, "Cutaneous leishmaniasis: recent developments in diagnosis and management," American Journal of Clinical Dermatology, vol. 16, no. 2, pp. 99-109, 2015.

[13] P. Minodier and P. Parola, "Cutaneous leishmaniasis treatment," Travel Medicine and Infectious Disease, vol. 5, no. 3, pp. 150-158, 2007.

[14] D. Pace, "Leishmaniasis," Journal of Infection, vol. 69, no. 1, pp. S10-S18, 2014. 
[15] J. Alvar, I. D. Vélez, C. Bern et al., "Leishmaniasis worldwide and global estimates of its incidence," PLoS One, vol. 7, no. 5, p. e35671, 2012.

[16] A. N. S. Maia-Elkhoury, Z. E. Yadon, M. I. S. Diaz, F. D. F. de Araujo Lucena, L. G. Castellanos, and M. J. Sanchez-Vazquez, "Exploring spatial and temporal distribution of cutaneous leishmaniasis in the Americas, 2001-2011," PLoS Neglected Tropical Diseases, vol. 10, no. 11, p. e0005086, 2016.

[17] C. F. Clarke, K. K. Bradley, J. H. Wright, and J. Glowicz, "Case report: emergence of autochthonous cutaneous leishmaniasis in northeastern Texas and southeastern Oklahoma," The American Journal of Tropical Medicine and Hygiene, vol. 88, no. 1, pp. 157-161, 2013.

[18] D. M. Pigott, S. Bhatt, N. Golding et al., "Global distribution maps of the leishmaniases," eLife, vol. 3, article e02851, 2014.

[19] M. Saroufim, K. Charafeddine, G. Issa et al., "Ongoing epidemic of cutaneous leishmaniasis among Syrian refugees, Lebanon," Emerging Infectious Diseases, vol. 20, no. 10, pp. 1712-1715, 2014.

[20] K. Hayani, A. Dandashli, and E. Weisshaar, "Cutaneous leishmaniasis in Syria: clinical features, current status and the effects of war," Acta Dermato-Venereologica, vol. 95, no. 1, pp. 62-66, 2015.

[21] M. Khosravani, M. D. Moemenbellah-Fard, M. Sharafi, and A. Rafat-Panah, "Epidemiologic profile of oriental sore caused by Leishmania parasites in a new endemic focus of cutaneous leishmaniasis, southern Iran," Journal of Parasitic Diseases, vol. 40, no. 3, pp. 1077-1081, 2016.

[22] S. M. Borghi, V. Fattori, I. Conchon-Costa, P. Pinge-Filho, W. R. Pavanelli, and W. A. Verri Jr., "Leishmania infection: painful or painless?," Parasitology Research, vol. 116, no. 2, pp. 465-475, 2017.

[23] E. Alam, O. Abbas, R. Moukarbel, and I. Khalifeh, "Cutaneous leishmaniasis: an overlooked etiology of midfacial destructive lesions," PLoS Neglected Tropical Diseases, vol. 10, no. 2, pp. 1-8, 2016.

[24] P. R. Criado, N. S. Valente, A. Noda, and W. Belda Junior, "Cutaneous New World leishmaniasis on a port-wine stain birthmark," Anais Brasileiros de Dermatologia, vol. 89, no. 4, pp. 669-670, 2014.

[25] L. F. D. Passero, C. Marques, I. Vale-Gato, C. E. P. Corbett, M. D. Laurenti, and G. Santos-Gomes, "Histopathology, humoral and cellular immune response in the murine model of Leishmania (Viannia) shawi," Parasitology International, vol. 59, no. 2, pp. 159-165, 2010.

[26] M. F. Lopes, A. C. Costa-da-Silva, and G. A. Dos Reis, "Innate Immunity to Leishmania Infection: Within Phagocytes," Mediators of Inflammation, vol. 2014, Article ID 754965, 7 pages, 2014.

[27] J. Conceição, R. Davis, P. P. Carneiro et al., "Characterization of neutrophil function in human cutaneous leishmaniasis caused by Leishmania braziliensis," PLOS Neglected Tropical Diseases, vol. 10, no. 5, p. e0004715, 2016.

[28] U. Ritter, F. Frischknecht, and G. van Zandbergen, "Are neutrophils important host cells for Leishmania parasites?," Trends in Parasitology, vol. 25, no. 11, pp. 505510, 2009.

[29] E. N. Loría-Cervera and F. J. Andrade-Narváez, "Animal models for the study of leishmaniasis immunology," Revista do Instituto de Medicina Tropical de São Paulo, vol. 56, no. 1, pp. 1-11, 2014.
[30] D. Santos-Mateus, F. Passero, A. Rodrigues et al., "The battle between Leishmania and the host immune system at a glance," International Trends in Immunity, vol. 4, no. 1, pp. 28-34, 2016.

[31] G. Gupta, S. Oghumu, and A. R. Satoskar, "Mechanisms of immune evasion in leishmaniasis," Advances in Applied Microbiology, vol. 82, pp. 155-184, 2013.

[32] A. Valério-Bolas, M. Pereira, G. Alexandre-Pires et al., "Intracellular and extracellular effector activity of mouse neutrophils in response to cutaneous and visceral Leishmania parasites," Cellular Immunology, vol. 335, pp. 76-84, 2019.

[33] A. R. Ambrosio and I. J. T. De Messias-Reason, "Leishmania (Viannia) braziliensis: interaction of mannose-binding lectin with surface glycoconjugates and complement activation. An antibody-independent defence mechanism," Parasite Immunology, vol. 27, no. 9, pp. 333-340, 2005.

[34] I. Evans-Osses, I. de Messias-Reason, and M. I. Ramirez, "The emerging role of complement lectin pathway in trypanosomatids: molecular bases in activation, genetic deficiencies, susceptibility to infection, and complement system-based therapeutics," Scientific World Journal, vol. 2013, Article ID 675898, 12 pages, 2013.

[35] M. Domínguez, I. Moreno, M. López-Trascasa, and A. Toraño, "Complement interaction with trypanosomatid promastigotes in normal human serum," Journal of Experimental Medicine, vol. 195, no. 4, pp. 451-459, 2002.

[36] A. Brittingham, C. J. Morrison, W. McMaster, B. McGwire, K. P. Chang, and D. M. Mosser, "Role of the Leishmania surface protease GP63 in complement fixation, cell adhesion, and resistance to complement-mediated lysis," The Journal of Immunology, vol. 155, no. 6, pp. 3102-3111, 1995.

[37] D. G. Russell, “The macrophage-attachment glycoprotein gp63 is the predominant C3-acceptor site on Leishmania mexicana promastigotes," European Journal of Biochemistry, vol. 164, no. 1, pp. 213-221, 1987.

[38] M. D. Laurenti, A. Örn, I. L. Sinhorini, and C. E. P. Corbett, "The role of complement in the early phase of Leishmania (Leishmania) amazonensis infection in BALB/c mice," Brazilian Journal of Medical and Biological Research, vol. 37, no. 3, pp. 427-434, 2004.

[39] D. L. Hoover, M. Berger, C. A. Nacy, W. T. Hockmeyer, and M. S. Meltzer, "Killing of Leishmania tropica amastigotes by factors in normal human serum," The Journal of Immunology, vol. 132, no. 2, pp. 893-897, 1984.

[40] S. d. C. Gonçalves-de-Albuquerque, R. Pessoa-e-Silva, L. A. M. Trajano-Silva et al., "The equivocal role of Th17 cells and neutrophils on immunopathogenesis of leishmaniasis," Frontiers in Immunology, vol. 8, no. 1437, pp. 1-11, 2017.

[41] E. D. Carlsen, Y. Liang, T. R. Shelite, D. H. Walker, P. C. Melby, and L. Soong, "Permissive and protective roles for neutrophils in leishmaniasis," Clinical and Experimental Immunology, vol. 182, no. 2, pp. 109-118, 2015.

[42] F. Tomiotto-Pellissier, B. T. S. Bortoleti, J. P. Assolini et al., "Macrophage polarization in leishmaniasis: broadening horizons," Frontiers in Immunology, vol. 9, pp. 1-12, 2018.

[43] N. C. Peters, J. G. Egen, N. Secundino et al., "In vivo imaging reveals an essential role for neutrophils in leishmaniasis transmitted by sand flies," Science, vol. 321, no. 5891, pp. 970-974, 2008. 
[44] G. M. A. C. Lima, A. L. Vallochi, U. R. Silva, E. M. A. F. Bevilacqua, M.. M. F. Kiffer, and I. A. Abrahamsohn, "The role of polymorphonuclear leukocytes in the resistance to cutaneous leishmaniasis," Immunology Letters, vol. 64, no. 2-3, pp. 145-151, 1998.

[45] L. M. A. Sousa, M. B. H. Carneiro, M. E. Resende et al., "Neutrophils have a protective role during early stages of Leishmania amazonensis infection in BALB/c mice," Parasite Immunology, vol. 36, no. 1, pp. 13-31, 2014.

[46] N. M. Tavares, T. Araújo-Santos, L. Afonso et al., "Understanding the mechanisms controlling Leishmania amazonensis infection in vitro: the role of LTB4 derived from human neutrophils," The Journal of Infectious Diseases, vol. 210, no. 4, pp. 656-666, 2014.

[47] H. Laufs, K. Müller, J. Fleischer et al., "Intracellular survival of Leishmania major in neutrophil granulocytes after uptake in the absence of heat-labile serum factors," Infection and Immunity, vol. 70, no. 2, pp. 826-835, 2002.

[48] A. B. Guimarães-Costa, M. T. C. Nascimento, G. S. Fromenta et al., "Leishmania amazonensis promastigotes induce and are killed by neutrophil extracellular traps," Proceedings of the National Academy of Sciences of the United States of America, vol. 106, no. 16, pp. 6748-6753, 2009.

[49] F. N. Morgado, M. T. C. Nascimento, E. M. Saraiva et al., “Are neutrophil extracellular traps playing a role in the parasite control in active American tegumentary leishmaniasis lesions?," PLOS One, vol. 10, no. 7, p. e0133063, 2015.

[50] L. Afonso, V. M. Borges, H. Cruz et al., "Interactions with apoptotic but not with necrotic neutrophils increase parasite burden in human macrophages infected with Leishmania amazonensis," Journal of Leukocyte Biology, vol. 84, no. 2, pp. 389-396, 2008.

[51] S. Nylen and S. Gautam, "Immunological perspectives of leishmaniasis," Journal of Global Infectious Diseases, vol. 2, no. 2, pp. 135-146, 2010.

[52] T. Cardoso, C. Bezerra, L. S. Medina et al., "Leishmania braziliensis isolated from disseminated leishmaniasis patients downmodulate neutrophil function," Parasite Immunology, vol. 41, p. e12620, 2019.

[53] H. Ishikawa, H. Hisaeda, M. Taniguchi et al., "CD4 ${ }^{+} \mathrm{V} \alpha 14$ NKT cells play a crucial role in an early stage of protective immunity against infection with Leishmania major," International Immunology, vol. 12, no. 9, pp. 1267-1274, 2000.

[54] J. Mattner, N. Donhauser, G. Werner-Felmayer, and C. Bogdan, "NKT cells mediate organ-specific resistance against Leishmania major infection," Microbes and Infection, vol. 8, no. 2, pp. 354-362, 2006.

[55] N. E. Rodríguez and M. E. Wilson, "Eosinophils and mast cells in leishmaniasis," Immunologic Research, vol. 59, no. 13, pp. 129-141, 2014.

[56] D. Liu and J. E. Uzonna, "The early interaction of Leishmania with macrophages and dendritic cells and its influence on the host immune response," Frontiers in Cellular and Infection Microbiology, vol. 2, pp. 83-90, 2012.

[57] L. L. Lanier, "Up on the tightrope: natural killer cell activation and inhibition," Nature Immunology, vol. 9, no. 5, pp. 495502, 2008.

[58] M. X. H. Sanabria, D. A. Vargas-Inchaustegui, L. Xin, and L. Soong, "Role of natural killer cells in modulating dendritic cell responses to Leishmania amazonensis infection," Infection and Immunity, vol. 76, no. 11, pp. 5100-5109, 2008.
[59] T. M. Scharton and P. Scott, "Natural killer cells are a source of interferon gamma that drives differentiation of CD4+ T cell subsets and induces early resistance to Leishmania major in mice," The Journal of Experimental Medicine, vol. 178, no. 2, pp. 567-577, 1993.

[60] M. D. Laurenti, M. Gidlund, D. M. Ura, I. L. Sinhorini, C. E. P. Corbett, and H. Goto, "The role of natural killer cells in the early period of infection in murine cutaneous leishmaniasis," Brazilian Journal of Medical and Biological Research, vol. 32, no. 3, pp. 323-325, 1999.

[61] C. Bogdan, "Natural killer cells in experimental and human leishmaniasis," Frontiers in Cellular and Infection Microbiology, vol. 2, no. 69, pp. 1-9, 2012.

[62] G. Van Zandbergen, N. Hermann, H. Laufs, W. Solbach, and T. Laskay, "Leishmania promastigotes release a granulocyte chemotactic factor and induce interleukin- 8 release but inhibit gamma interferon-inducible protein 10 production by neutrophil granulocytes," Infection and Immunity, vol. 70, no. 8, pp. 4177-4184, 2002.

[63] T. Lieke, S. Nyln, L. Eidsmo et al., "Leishmania surface protein gp63 binds directly to human natural killer cells and inhibits proliferation," Clinical and Experimental Immunology, vol. 153, no. 2, pp. 221-230, 2008.

[64] L. I. Pereira, M. L. Dorta, A. J. Pereira et al., "Increase of NK cells and proinflammatory monocytes are associated with the clinical improvement of diffuse cutaneous leishmaniasis after immunochemotherapy with BCG/Leishmania antigens," The American Journal of Tropical Medicine and Hygiene, vol. 81, no. 3, pp. 378-383, 2009.

[65] I. C. Cañeda-Guzmán, N. Salaiza-Suazo, E. A. Fernández-Figueroa, G. Carrada-Figueroa, M. Aguirre-García, and I. Becker, "NK cell activity differs between patients with localized and diffuse cutaneous leishmaniasis infected with Leishmania mexicana: a comparative study of TLRs and cytokines," PLoS One, vol. 9, no. 11, p. e112410, 2014.

[66] A. Classen, J. Lloberas, and A. Celada, "Macrophage activation: classical Vs. alternative," Methods in Molecular Biology, vol. 531, pp. 29-43, 2009.

[67] F. O. Martinez, L. Helming, and S. Gordon, "Alternative activation of macrophages: an immunologic functional perspective," Annual Review of Immunology, vol. 27, no. 1, pp. 451-483, 2009.

[68] M. Rath, I. Müller, P. Kropf, E. I. Closs, and M. Munder, "Metabolism via arginase or nitric oxide synthase: two competing arginine pathways in macrophages," Frontiers in Immunology, vol. 5, pp. 1-10, 2014.

[69] A. Y. el Kadaro, A. Gaafar, A. M. el Hassan et al., "The pathology of cutaneous leishmaniasis due to Leishmania major in Sudan," The American Journal of Tropical Medicine and Hygiene, vol. 52, no. 5, pp. 438-442, 1995.

[70] E. Mougneau, F. Bihl, and N. Glaichenhaus, "Cell biology and immunology of Leishmania," Immunological Reviews, vol. 240, no. 1, pp. 286-296, 2011.

[71] J. I. Odegaard, R. R. Ricardo-Gonzalez, M. H. Goforth et al., "Macrophage-specific PPAR $\gamma$ controls alternative activation and improves insulin resistance," Nature, vol. 447, no. 7148, pp. 1116-1120, 2007.

[72] M. M. Kane and D. M. Mosser, "The role of IL-10 in promoting disease progression in leishmaniasis," The Journal of Immunology, vol. 166, no. 2, pp. 1141-1147, 2001. 
[73] E. von Stebut and S. Tenzer, "Cutaneous leishmaniasis: Distinct functions of dendritic cells and macrophages in the interaction of the host immune system with Leishmania major," International Journal of Medical Microbiology, vol. 308, no. 1, pp. 206-214, 2018.

[74] C. Hölscher, B. Arendse, A. Schwegmann, E. Myburgh, and F. Brombacher, "Impairment of alternative macrophage activation delays cutaneous leishmaniasis in nonhealing BALB/c mice," The Journal of Immunology, vol. 176, no. 2, pp. 11151121, 2006.

[75] J. França-Costa, J. van Weyenbergh, V. S. Boaventura et al., "Arginase I, polyamine, and prostaglandin E2 pathways suppress the inflammatory response and contribute to diffuse cutaneous leishmaniasis," The Journal of Infectious Diseases, vol. 211, no. 3, pp. 426-435, 2015.

[76] S. M. Muxel, M. F. Laranjeira-Silva, R. A. Zampieri, and L. M. Floeter-Winter, "Leishmania (Leishmania) amazonensis induces macrophage miR-294 and miR-721 expression and modulates infection by targeting NOS2 and Larginine metabolism," Scientific Reports, vol. 7, no. 1, pp. 1-15, 2017.

[77] A. Badirzadeh, T. Taheri, F. Abedi-Astaneh et al., "Arginase activity ofLeishmaniaisolated from patients with cutaneous leishmaniasis," Parasite Immunology, vol. 39, no. 9, pp. 110, 2017.

[78] D. Feijó, R. Tibúrcio, M. Ampuero, C. Brodskyn, and N. Tavares, "Dendritic cells and Leishmania infection: adding layers of complexity to a complex disease," Journal of Immunology Research, vol. 2016, Article ID 3967436, 9 pages, 2016.

[79] F. T. Silveira, R. Lainson, C. M. C. Gomes, M. D. Laurenti, and C. E. P. Corbett, "Reviewing the role of the dendritic Langerhans cells in the immunopathogenesis of American cutaneous leishmaniasis," Transactions of the Royal Society of Tropical Medicine and Hygiene, vol. 102, no. 11, pp. 10751080, 2008

[80] É. L. Vieira, T. S. Keesen, P. R. Machado et al., "Immunoregulatory profile of monocytes from cutaneous leishmaniasis patients and association with lesion size," Parasite Immunology, vol. 35, no. 2, pp. 65-72, 2013.

[81] L. Soong, C. A. Henard, and P. C. Melby, "Immunopathogenesis of non-healing American cutaneous leishmaniasis and progressive visceral leishmaniasis," Seminars in Immunopathology, vol. 34, no. 6, pp. 735-751, 2012.

[82] F. T. Silveira, R. Lainson, and C. E. P. Corbett, "Clinical and immunopathological spectrum of American cutaneous leishmaniasis with special reference to the disease in Amazonian Brazil: a review," Memórias do Instituto Oswaldo Cruz, vol. 99, no. 3, pp. 239-251, 2004.

[83] F. T. Silveira, R. Lainson, C. M. De Castro Gomes, M. D. Laurenti, and C. E. P. Corbett, "Immunopathogenic competences of Leishmania $(V$.) braziliensis and $L$. (L.) amazonensis in American cutaneous leishmaniasis," Parasite Immunology, vol. 31, no. 8, pp. 423-431, 2009.

[84] K. Kautz-Neu, M. Noordegraaf, S. Dinges et al., "Langerhans cells are negative regulators of the anti-Leishmania response," The Journal of Experimental Medicine, vol. 208, no. 5, pp. 885-891, 2011.

[85] L. R. Castellano, D. C. Filho, L. Argiro et al., "Th1/Th2 immune responses are associated with active cutaneous leishmaniasis and clinical cure is associated with strong interferon- $\gamma$ production," Human Immunology, vol. 70, no. 6, pp. 383-390, 2009.
[86] R. L. E. Cano and H. D. E. Lopera, "Introduction to T and B lymphocytes," in Autoimmunity: from bench to bedside, J. M. Anaya, Y. Shoenfeld, A. Rojas-Villarraga, R. A. Levy, and R. Cervera, Eds., vol. 5, pp. 77-95, El Rosario University Press, Bogota (Colombia), 2013.

[87] R. Bankoti, K. Gupta, A. Levchenko, and S. Stager, "Marginal zone B cells regulate antigen-specific T cell responses during infection," The Journal of Immunology, vol. 188, no. 8, pp. 3961-3971, 2012.

[88] D. Rodriguez-Pinto, N. G. Saravia, and D. McMahon-Pratt, "CD4 T cell activation by B cells in human Leishmania (Viannia) infection," BMC Infectious Diseases, vol. 14, no. 1, pp. 1-13, 2014.

[89] N. Wanasen, L. Xin, and L. Soong, "Pathogenic role of B cells and antibodies in murine Leishmania amazonensis infection," International Journal for Parasitology, vol. 38, no. 3-4, pp. 417-429, 2008.

[90] B. Scorza, E. Carvalho, and M. Wilson, "Cutaneous manifestations of human and murine leishmaniasis," International Journal of Molecular Sciences, vol. 18, no. 6, pp. 1296-1322, 2017.

[91] F. Woelbing, S. L. Kostka, K. Moelle et al., "Uptake of Leishmania major by dendritic cells is mediated by Fcgamma receptors and facilitates acquisition of protective immunity," The Journal of Experimental Medicine, vol. 203, no. 1, pp. 177-188, 2006.

[92] P. Scott, P. Natovitz, and A. Sher, "B lymphocytes are required for the generation of $\mathrm{T}$ cells that mediate healing of cutaneous leishmaniasis," The Journal of Immunology, vol. 137, no. 3, pp. 1017-1021, 1986.

[93] R. Mukbel, C. A. Petersen, and D. E. Jones, "Soluble factors from Leishmania major-specific $\mathrm{CD}^{+} \mathrm{T}$ cells and $\mathrm{B}$ cells limit L. amazonensis amastigote survival within infected macrophages," Microbes and Infection, vol. 8, no. 9-10, pp. 2547-2555, 2006.

[94] K. N. Gibson-Corley, "Understanding the role of B cells during Leishmania amazonensis infection," in Graduate Theses and Dissertations, p. 11418, Iowa State University, 2010.

[95] R. Kumar and C. Engwerda, "Vaccines to prevent leishmaniasis," Clinical \& Translational Immunology, vol. 3, no. 3, p. e13, 2014.

[96] C. Pirmez, M. Yamamura, K. Uyemura, M. Paes-Oliveira, F. Conceição-Silva, and R. L. Modlin, "Cytokine patterns in the pathogenesis of human leishmaniasis," The Journal of Clinical Investigation, vol. 91, no. 4, pp. 1390-1395, 1993.

[97] G. Caceres-Dittmar, F. J. Tapia, M. A. Sénchez et al., "Determination of the cytokine profile in American cutaneous leishmaniasis using the polymerase chain reaction," Clinical and Experimental Immunology, vol. 91, no. 3, pp. 500-505, 1993.

[98] E. T. Guimarães, L. A. Santos, R. Ribeiro dos Santos, M. M. Teixeira, W. L. C. dos Santos, and M. B. P. Soares, "Role of interleukin-4 and prostaglandin $\mathrm{E}_{2}$ in Leishmania amazonensis infection of BALB/c mice," Microbes and Infection, vol. 8, no. 5, pp. 1219-1226, 2006.

[99] K. González, R. Diaz, A. F. Ferreira et al., "Histopathological characteristics of cutaneous lesions caused by Leishmania Viannia panamensis in Panama," Revista do Instituto de Medicina Tropical de São Paulo, vol. 60, no. 0, pp. 1-9, 2018.

[100] D. McMahon-Pratt and J. Alexander, "Does the Leishmania major paradigm of pathogenesis and protection hold for 
New World cutaneous leishmaniases or the visceral disease?," Immunological Reviews, vol. 201, no. 1, pp. 206-224, 2004.

[101] A. Ehrlich, T. M. Castilho, K. Goldsmith-Pestana et al., "The immunotherapeutic role of regulatory $\mathrm{T}$ cells in Leishmania (Viannia) panamensis infection," The Journal of Immunology, vol. 193, no. 6, pp. 2961-2970, 2014.

[102] K. J. Gollob, L. R. V. Antonelli, D. R. Faria, T. S. L. Keesen, and W. O. Dutra, "Immunoregulatory mechanisms and CD4-CD8- (double negative) $\mathrm{T}$ cell subpopulations in human cutaneous leishmaniasis: A balancing act between protection and pathology," International Immunopharmacology, vol. 8, no. 10, pp. 1338-1343, 2008.

[103] L. R. V. Antonelli, W. O. Dutra, R. R. Oliveira et al., "Disparate Immunoregulatory Potentials for Double-Negative (CD4 $-\mathrm{CD} 8-) \alpha \beta$ and $\gamma \delta$ T Cells from Human Patients with Cutaneous Leishmaniasis," Infection and Immunity, vol. 74, no. 11, pp. 6317-6323, 2006.

[104] R. Ferraz, C. F. Cunha, M. I. F. Pimentel et al., "CD3 ${ }^{+-}$ $\mathrm{CD} 4{ }^{\text {neg }} \mathrm{CD} 8{ }^{\text {neg }}$ (double negative) $\mathrm{T}$ lymphocytes and NKT cells as the main cytotoxic-related-CD107a ${ }^{+}$cells in lesions of cutaneous leishmaniasis caused by Leishmania (Viannia) braziliensis," Parasites \& Vectors, vol. 10, no. 1, 2017.

[105] Z. Mou, D. Liu, I. Okwor, P. Jia, K. Orihara, and J. E. Uzonna, "MHC class II restricted innate-like double negative T cells contribute to optimal primary and secondary immunity to Leishmania major," PLoS Pathogens, vol. 10, no. 9, p. e1004396, 2014.

[106] T. T. Espir, T. S. Guerreiro, M. . F. Naiff et al., "Evaluation of different diagnostic methods of American cutaneous leishmaniasis in the Brazilian Amazon," Experimental Parasitology, vol. 167, no. 167, pp. 1-6, 2016.

[107] H. C. Neitzke-Abreu, M. S. Venazzi, R. B. de Lima Scodro et al., "Cutaneous leishmaniasis with atypical clinical manifestations: case report," IDCases, vol. 1, no. 3, pp. 60-62, 2014.

[108] L. F. Oliveira, A. O. Schubach, M. M. Martins et al., "Systematic review of the adverse effects of cutaneous leishmaniasis treatment in the New World," Acta Tropica, vol. 118, no. 2, pp. 87-96, 2011.

[109] R. L. Charlton, B. Rossi-Bergmann, P. W. Denny, and P. G. Steel, "Repurposing as a strategy for the discovery of new anti-leishmanials: the-state-of-the-art," Parasitology, vol. 145, no. 2, pp. 219-236, 2018.

[110] A. Ponte-Sucre, F. Gamarro, J.-C. Dujardin et al., "Drug resistance and treatment failure in leishmaniasis: a 21st century challenge," PLoS Neglected Tropical Diseases, vol. 11, no. 12, p. e0006052, 2017.

[111] A. J. Martínez-Valencia, C. F. Daza-Rivera, M. Rosales-Chilama et al., "Clinical and parasitological factors in parasite persistence after treatment and clinical cure of cutaneous leishmaniasis," PLoS Neglected Tropical Diseases, vol. 11, no. 7, pp. e0005713-e0005715, 2017.

[112] S. V. C. B. Gonçalves and C. H. N. Costa, "Treatment of cutaneous leishmaniasis with thermotherapy in Brazil: an efficacy and safety study," Anais Brasileiros de Dermatologia, vol. 93, no. 3, pp. 347-355, 2018.

[113] A. Uribe-Restrepo, A. Cossio, M. M. Desai, D. Dávalos, and M. . M. Castro, "Interventions to treat cutaneous leishmaniasis in children: a systematic review," PLoS Neglected Tropical Diseases, vol. 12, no. 12, pp. 1-16, 2018.

[114] A. N. S. Maia-Elkhoury, S. Y. O. B. Valadas, L. PuppimBuzanovsky, F. Rocha, and M. J. Sanchez-Vazquez, "SisLeish: a multi-country standardized information system to monitor the status of leishmaniasis in the Americas," PLoS Neglected Tropical Diseases, vol. 11, no. 9, p. e0005868, 2017.

[115] J. D. Gutierrez, R. Martínez-Vega, J. Ramoni-Perazzi et al., "Environmental and socio-economic determinants associated with the occurrence of cutaneous leishmaniasis in the northeast of Colombia," Transactions of the Royal Society of Tropical Medicine and Hygiene, vol. 111, no. 12, pp. 564$571,2017$.

[116] G. Herrera, A. Teherán, I. Pradilla, M. Vera, and J. D. Ramírez, "Geospatial-temporal distribution of tegumentary leishmaniasis in Colombia (2007-2016)," PLoS Neglected Tropical Diseases, vol. 12, no. 4, p. e0006419, 2018.

[117] C. Sanford, "Urban medicine: threats to health of travelers to developing world cities," Journal of Travel Medicine, vol. 11, no. 5, pp. 313-327, 2004. 


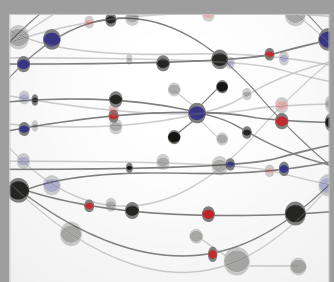

The Scientific World Journal
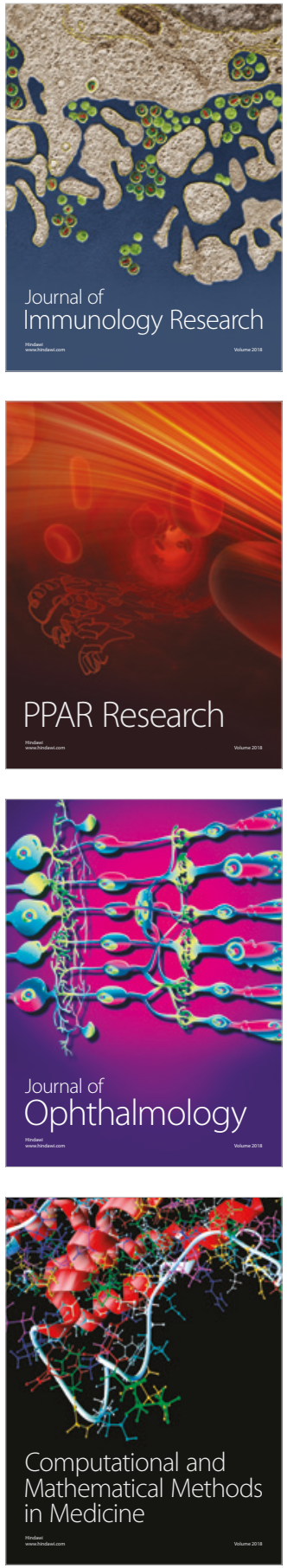

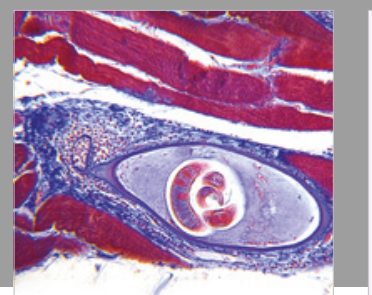

Gastroenterology Research and Practice

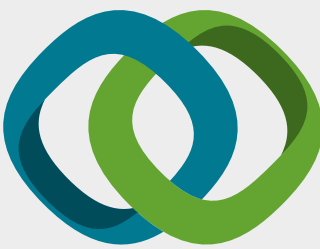

\section{Hindawi}

Submit your manuscripts at

www.hindawi.com
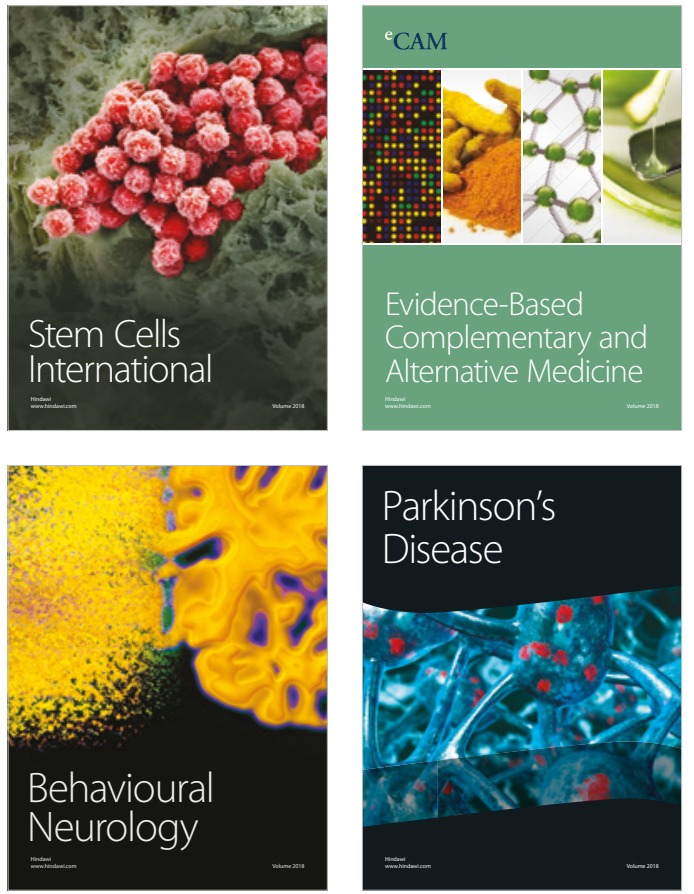

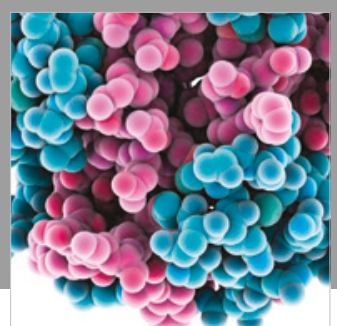

ournal of

Diabetes Research

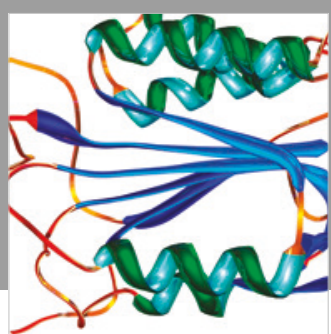

Disease Markers
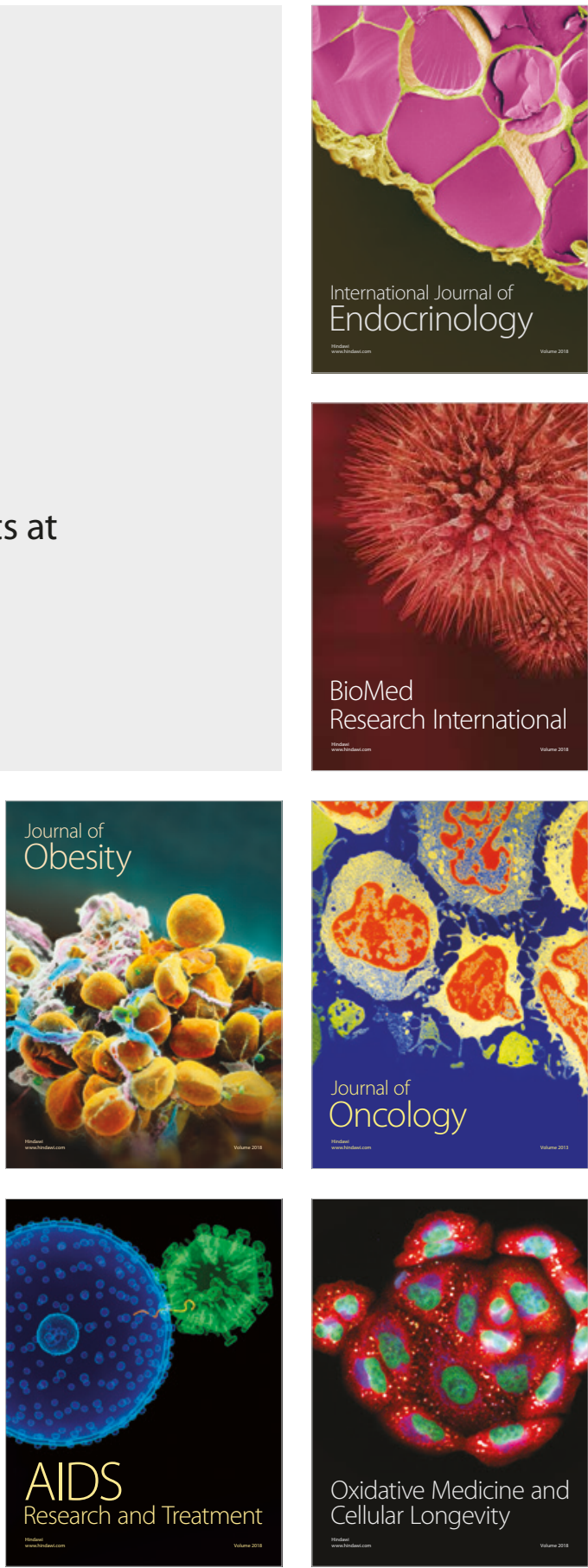